\title{
"No front dos sexos": a marcha de enfermeiras brasileiras para a conquista do serviço militar
}

\author{
"At the front of the sexes": the march of Brazilian nurses to gain military service
}

"Al front de los sexos": la marcha de enfermeras brasileñas a la conquista del servicio militar

Alexandre Barbosa de Oliveira1, Tânia Cristina Franco Santos², Maria Itayra Coelho de Souza Padilha³, Angélica Ribeiro Pinto de Oliveira ${ }^{4}$, Maria Angélica de Almeida Peres ${ }^{5}$, Mariane Bonfante Cesario ${ }^{6}$

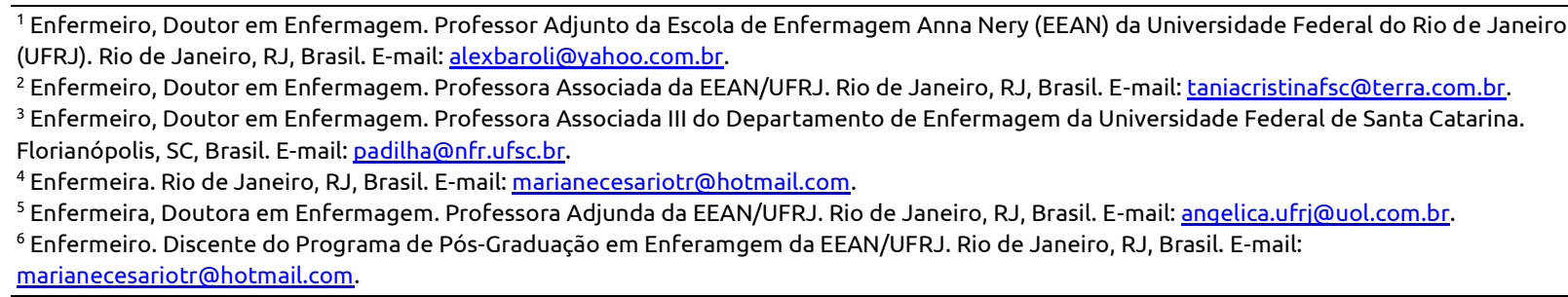

\section{RESUMO}

Estudo histórico-social que objetivou analisar as iniciativas de incorporação oficial de enfermeiras brasileiras no campo militar durante a primeira metade do século XX e discutir as implicações da incorporação oficial de enfermeiras brasileiras no Serviço Militar, no bojo da Segunda Guerra Mundial. As fontes primárias foram documentos escritos e iconográficos. Os dados foram classificados, contextualizados e analisados por meio do método histórico, e tratados à luz da Teoria do Mundo Social de Pierre Bourdieu e de estudos sobre Minha História das Mulheres, de Michelle Perrot. Os resultados evidenciaram que as iniciativas de incorporação oficial de mulheres enfermeiras em instituições militarizadas no Brasil foram definidas pelos efeitos simbólicos da dominação masculina, que ditaram os limites e possibilidades destas enfermeiras na ocupação de posições de poder e prestígio nas Forças Armadas do país à época. Foi uma história de luta em que se (re)definiu a divisão sexual do trabalho no campo militar.

Descritores: Enfermagem; História da Enfermagem; Enfermagem Militar.

\section{ABSTRACT}

The objective of this historical-social study was to analyze the initiatives of officially incorporating Brazilian nurses in the military field during the first half of the $20^{\text {th }}$ century, and discuss on the implications of incorporating Brazilian nurses in Military Service during World War II. The primary sources were written and iconographic documents. Data were classified, contextualized and analyzed by the historical method and treated under the light of the Social World Theory by Pierre Bourdieu and History of Women by Michelle Perrot. Results showed that the initiatives to make an official incorporation of Brazilian nurses in militarized institutions in Brazil were defined by the symbolic effects of masculine domination, which dictated the limits and possibilities of those nurses in occupying positions of power and prominence in the Brazilian Army at the time. It was a history of battles that (re)defined sexual division of labor in the military field.

Descriptors: Nursing; History of Nursing; Military Nursing.

\section{RESUMEN}

Estudio histórico-social objetivando analizar las iniciativas de incorporación oficial de enfermeras brasileñas al campo militar, durante la primera mitad del siglo XX y discutir las implicancias de la incorporación oficial de enfermeras brasileñas al Servicio Militar, durante la Segunda Guerra Mundial. Las fuentes primarias fueron documentos escritos e iconográficos. Los datos fueron clasificados, contextualizados y analizados mediante método histórico, y tratados según la Teoría del Mundo Social de Pierre Bordieu y de estudios sobre Historia de las Mujeres, de Michelle Perrot. Los resultados evidenciaron que las iniciativas de incorporación oficial de enfermeras en instituciones militarizadas en Brasil fueron definidas por los efectos simbólicos de dominación masculina, que dictaron límites y posibilidades de dichas enfermeras en la ocupación de posiciones de poder y prestigio en la Fuerzas Armadas nacionales en la época. Fue una historia de lucha en la que se (re)definió la división sexual del trabajo en el campo militar.

Descriptores: Enfermería; Historia de la Enfermería; Enfermería Militar. 


\section{CONSIDERAÇÕES INICIAIS}

Ao longo de sua história, a enfermagem quase sempre esteve direta, pública e simbolicamente envolvida em situações de guerra. Nesses momentos de caos, decisivos e importantes da história da humanidade, inúmeros são os exemplos de que as mulheres se alinharam à prática de enfermagem, o que serviu de bom argumento para tornar possível sua aparição e atuação pública. Outrossim, é lugar comum do discurso político e da literatura a ideia de que as guerras mudaram as relações entre os sexos, e deram às mulheres novos poderes $^{(1)}$.

No Brasil, durante o período entre guerras (19181939) e com mais afinco nos anos da Segunda Guerra Mundial (1939-1945), as demandas sociais, políticas e sanitárias favoreceram o chamamento de mulheres enfermeiras para participarem, caso fosse necessário, dos cenários de conflitos civis e militares, o que contribuiu para sedimentar a visibilidade de um modelo de profissional respaldado em aspectos altruístas e patrióticos. Neste ínterim, as proposições e embates para a inclusão de enfermeiras nas Forças Armadas do país começam a ganhar força(1).

Diante disso é que foram traçados os objetivos deste estudo: analisar as iniciativas de incorporação oficial de enfermeiras brasileiras no campo militar, durante a primeira metade do século XX; e discutir as implicações da incorporação oficial de enfermeiras brasileiras no Serviço Militar, no bojo da Segunda Guerra Mundial.

Estudos derivados de dissertações de mestrado e teses de doutorado na linha de pesquisa de História da Enfermagem, que tratam da incorporação de enfermeiras no campo militar e de sua atuação da Segunda Guerra Mundial, vem sendo alvo de difusão em periódicos científicos nos últimos anos, dos quais enfatizamos os produzidos sobre a história das enfermeiras da Força Expedicionária Brasileira(2-4), os quais constituem a grande maioria. Contudo, desta temática ainda há muito o que se elucidar! Assim, a contribuição do presente artigo em relação aos já publicados sobre este tema é a de se aprofundar a discussão da problemática acerca dos limites da admissão de mulheres no campo militar, além de tratar de uma história de luta e resistência de enfermeiras demarcada pelos efeitos simbólicos da dominação masculina, os quais se fizeram explícitos na materialização da divisão sexual do trabalho nas Forças Armadas brasileiras.

\section{ABORDAGEM METODOLÓGICA E TEÓRICA}

Trata-se de um estudo histórico-social, de abordagem qualitativa, cujas fontes primárias constaram de documentos escritos oficiais (constituições, leis, decretos, portarias, projetos de lei) e não-oficiais (jornais, revistas, anais de congresso, livros raros), além de documentos iconográficos (capa de revista e fotografia) referentes ao período do entre guerras (1918-1939) e da Segunda Guerra Mundial (1939-1945).

Estas fontes foram coletadas entre setembro de 2008 e outubro de 2010, nos seguintes acervos da cidade do Rio de Janeiro: Fundação Biblioteca Nacional (material físico e virtual); Arquivo Histórico do Exército e Acervo da Força Expedicionária Brasileira (Palácio Duque de Caxias); e Centro de Documentação da Escola de Enfermagem Anna Nery (Universidade Federal do Rio de Janeiro).

O desenvolvimento do estudo pautou-se na consideração das etapas fundamentais preconizadas pelo método histórico(5). Desse modo, após a identificação, seleção, classificação cronológica e temática das fontes primárias, procedeu-se a validação das mesmas por meio da crítica externa, que trata da natureza, autoria e procedência dos documentos, e da crítica interna, que trata da veracidade dos fatos contidos nos documentos, e da apreensão e significância de seus conteúdos. Рara amplificação das possibilidades de interpretação das fontes, aproveitamos as técnicas de análise documental e de análise iconográfica.

As fontes secundárias, constituídas de artigos e livros acerca da História da Enfermagem (Militar), da História das Mulheres e da História do Brasil, consubstanciaram a análise dos dados derivados das fontes primárias selecionadas.

As matrizes de análise empregadas consideraram os elementos simbólicos contidos no corpus documental. Estas matrizes levaram em conta as mensagens implícitas, seus sentidos e significações, e favoreceram o processo de contextualização, análise e interpretação dos dados, que também foram tratados à luz dos conceitos e noções da Teoria do Mundo Social do sociólogo Pierre Bourdieu (6) e dos estudos sobre a História das Mulheres da historiadora Michelle Perrot ${ }^{(7)}$.

Ademais, a conjugação destes dois autores como referencial teórico deste estudo favoreceu o entendimento das zonas de poder e dominação, e seus efeitos sobre a possibilidade de inclusão de enfermeiras brasileiras no Serviço Militar, o que auxiliou de modo 
significativo nas versões e interpretações aqui construídas.

No que diz respeito aos aspectos ético-legais, cumpre ressaltar que o projeto de doutoramento do qual originou este estudo obteve aprovação do Comitê de Ética em Pesquisa da Escola de Enfermagem Anna Nery e Hospital Escola São Francisco de Assis, por meio do Protocolo $n^{\circ}$ 068, datado de 27 de agosto de 2008.

\section{RESULTADOS E DISCUSSÃO}

Ato viril por excelência, as guerras têm a tendência de consolidar os papéis tradicionais. Em uma disciplina reforçada, apoiada por um discurso voluntariamente culpabilizador, notadamente para as mulheres, cada sexo, em geral, é distintamente mobilizado a serviço da Pátria: os homens à frente, as mulheres à retaguarda. Se na prática, tal divisão sexual do trabalho bem definiu as possibilidades e limites entre homens e mulheres, na teoria, as guerras são tidas como universos de homens, e de armas pesadas, cavalos, luta, fome, destruição, doenças e mortes ${ }^{(7)}$.

Não obstante, muitas mulheres gostariam de ter sido combatente, ter subido em muralhas, vestido fardas, portado medalhas, manejado espadas ou fuzis, assim como Clorinda, Joana d’Arc, Maria Quitéria de Jesus ou Anita Garibaldi. Mas, as armas geralmente lhes foram proibidas. Assim é que os hospitais foram o que especialmente lhes coube nas guerras, conflitos e revoluções, até a volta da paz, quando deveriam, a priori, sair de cena e retornar para o espaço doméstico ${ }^{(4,7)}$.

Desse modo é que a enfermagem, dentre todas as profissões geralmente tidas como femininas, foi a que mais se fez aceita para o aproveitamento de mulheres nas masculinizadas organizações militares. Assim, elas foram aproveitadas como agregadas, as que acompanhavam os exércitos para cuidar dos feridos, como convocadas, incluídas oficialmente às instituições militares nos períodos de guerra, e ainda como incorporadas, efetivadas em tempos de paz, quando passavam a ter direito a uma carreira, promoções e condições muito próximas dos homens, mas com restrições à ocupação de funções de prestígio, tais como às relacionadas ao combate e ao comando ${ }^{(8-9)}$.

Por certo, a atuação de mulheres enfermeiras em situações de guerra não é fato novo. Vem da inglesa Florence Nightingale (1820-1910), expoente da enfermagem em escala mundial(10), e de Anna Nery (1814-
1880), o exemplo brasileiro(11), as referências prévias emblemáticas que bem serviram para demarcar a presença, viabilidade e necessidade de enfermeiras em situações bélicas, mesmo que na retaguarda. Assim, as aparições de mulheres enfermeiras, comumente respaldadas e legitimadas pelos governos e instituições, regalaram, em diferentes tempos, possibilidades que recondicionaram a visibilidade delas nos espaços públicos, e modificaram, por vezes, a ordem das coisas.

Com efeito, a convocação de contingentes femininos só entrou na pauta das discussões políticas quando a mulher passou a ser vista como uma alternativa ao problema dos efetivos, pois, ao ocuparem posições nas ditas "atividades meio", as mulheres começaram a liberar os homens para as "atividades fim", ou seja, para as áreas combatentes. Bom exemplo disso ocorreu durante a Primeira Guerra Mundial (1914-1918), que foi cenário de atuação dos primeiros corpos femininos militarizados ${ }^{(8)}$.

Aliás, com a eclosão da Primeira Grande Guerra, ocorreu a aproximação das sufragistas da Europa e dos Estados Unidos com as lideranças da enfermagem, em torno das demandas pela elevação de postos na hierarquia militar. No entanto, este aparente ganho para as novas profissionais teve resultados dúbios a longo prazo, uma vez que a compatibilidade entre a vida militar e as qualidades de disciplina passou a promover esquemas de administração taylorista nos hospitais, com vistas à racionalização do trabalho(12).

No início da Primeira Guerra, não se cogitava a entrada do Brasil no confronto, o que só aconteceu de fato no dia 03 de outubro 1917. Рara a contenda, o Governo Venceslau Brás enviou uma missão médica, que não contou com a participação de enfermeiras ${ }^{(13)}$. Nesta época, um aspecto que merece destaque é o de que o país não possuía mulheres enfermeiras nos quadros de suas organizações militares, a despeito da existência de homens enfermeiros incorporados no Corpo de Saúde do Exército desde o século XIX. Mais tarde, em 1921, foi promulgado o Decreto $n^{\circ} 15.230$, que regulamentou a formação de enfermeiros no Corpo de Saúde do Exército, mas que não chegou a contar com a participação feminina nos quadros de enfermagem desta Força.

Ademais, há que se mencionar que é notável na história das mulheres do país, marcada pela importação das ideias do mundo europeu e norte-americano, um esforço em se alterar as desigualdades de gênero. Por certo, no entre guerras, a participação política e social das 
mulheres brasileiras passou a ganhar especial vulto: com a fundação da Liga pela Emancipação Internacional da Mulher no Rio de Janeiro (1919), grupo de estudos liderado por Bertha Maria Júlia Lutz e Maria Lacerda de Moura, que lutou pela igualdade das mulheres; com a Semana da Arte Moderna (1922), marco do modernismo brasileiro em que participaram renomados(as) artistas e intelectuais; e com a criação do Partido Comunista Brasileiro (1922), que contou com expressiva atuação feminina.

Tais movimentos fizeram parte de uma evolução crescente em busca de igualdade e inclusão, e que gerou reações em diversos âmbitos. No do trabalho, por exemplo, a inserção de mulheres fez florescerem entre os homens certas precauções e preocupações pela possibilidade de efeitos perturbadores na divisão material e simbólica de seus espaços circunscritos no campo social. Por ilustração, uma crônica publicada em 27 de setembro de 1930, no jornal Folha da Noite, explorou a hipotética masculinização das mulheres que reivindicavam direitos, um dos estereótipos que thes era mais imputado, e declarou que essas "esquisitas senhoras que estão levantando pelo mundo todo o clamor pela conquista dos direitos da mulher, não se deveriam chamar feministas, mas masculinistas." Isto porque, tais senhoras "vestiam-se ousadamente como homens".

Nessa subversão da ordem social, essas que se masculinizavam no tipo e que desejavam masculinizar-se nos direitos, propunham uma perigosa igualdade política e jurídica dos dois sexos, e estava evidente que mais tarde proporiam também a equiparação proliferante, inclusive no campo militar ${ }^{(14)}$. Além de tais ideias, o cronista mencionou o seguinte:

Insensivel para as coisas do coração, inacessível às ruínas e superior às pequeninas vaidades próprias do seu sexo - a mulher moderna, sem que o perceba, se masculiniza para assombro nosso, que espreitamos estupefatos a brusca transformação verificada nos últimos anos. O tipo incrível da Virago - ai temo-lo agora, multiplicado e espalhado por todos os cantos da terra... (...) Mulheres nos governos, nas repartições públicas, nos exércitos, nas fábricas - em tudo, enfim, onde havia homens antigamente...

Nos primeiros decênios do século $X X$, tais discursos buscavam comumente reiterar e legitimar a reclusão da mulher nos espaços que fossem privados, ao tempo que buscavam consagrar sua subordinação e inferioridade em relação ao homem. O esforço em registrar a inferioridade das mulheres no meio jornalístico, constitui-se em uma violência simbólica, porque difundia o despropósito das preocupações femininas (dominadas), ao contrário das masculinas (dominantes) ${ }^{(6)}$.

Em compensação, o esgotamento do modelo oligárquico do Estado brasileiro, que foi derrubado com a Revolução de 1930 liderada por Getúlio Dornelles Vargas, gerou uma possibilidade de se redefinir e de se reorganizar a vida política do país, ocasião que se mostrou propícia à participação feminina. Nessa conjuntura, a mulher, desde que regida pelos princípios religiosos e morais católicos, teria uma contribuição única e original a dar. Há também que se considerar que, com a Revolução, a Igreja Católica passou a reaver espaços e poderes sobre a vida política e social brasileira, e, nesta empreitada, aproximou-se da causa feminina, e por extensão, das enfermeiras ${ }^{(15-16)}$.

No bojo da década de 1930, que foi marcada pela crescente urbanização e rápida evolução do setor industrial do país, ampliou-se a participação da mulher para além das fronteiras domésticas. Com as ofertas de emprego no comércio e nas indústrias, oportunizou-se a presença da mulher de classe média no mundo do trabalho, em sintonia com a situação de outros países. Neste processo, o rádio e a imprensa (feminina) foram bons vetores das rápidas mudanças da vida moderna ${ }^{(16)}$.

Ainda no alvorecer da Nova República, em 1932, as mulheres brasileiras conquistaram o direito ao voto com a publicação do Decreto $n^{\circ} 21.076$, que instituiu o Código Eleitoral Brasileiro, cujo artigo $2^{\circ}$ disciplinou que era eleitor "o cidadão maior de 21 anos, sem distinção de sexo". Pela primeira vez, as mulheres tornavam-se eleitoras e elegíveis, o que significava um grande passo em termos de cidadania feminina.

Sobre esta conquista, as mulheres sofreram reações desfavoráveis em uma clara intenção de se menosprezálas, para assim mantê-las em seu lugar - a casa - e com sua identidade sexual inalterada - inferior e oposta a dos homens. Através de sátiras e charges, fazia-se ver a feminista como feia e masculinizada(17). O artigo As mulheres, a política e a defesa nacional, da revista paulistana Careta, é um bom exemplo. Nele, noticia-se a proposta de um general, segundo o qual as mulheres, se desejassem votar, deveriam também "servir" ao Exército. O comentário sarcástico dele, publicado em 14 de janeiro 
de 1933, foi o seguinte: "Sendo, como se sabe, em geral pouco bonitas as mulheres que andam metidas em política, conduzi-las ao serviço militar obrigatório seria dotar o Exército, com economia e facilidade, de vastas baterias de artilharia pesada. Toda a gente sabe que é impossível fazer a guerra moderna sem canhões."

Apesar de toda essa situação, a conquista do voto foi logo incorporada à Constituição Brasileira promulgada em 1934. Assim, o artigo 113 fixou o seguinte: "Todos são iguais perante a lei. Não haverá privilégios, nem distinções, por motivo de nascimento, sexo, raça, profissões próprias ou dos pais, classe social, riqueza, crenças religiosas ou ideias políticas." Em adição a este ganho, vale o registro de que, até então, as constituições tão somente afirmavam, de forma genérica, o princípio da igualdade de todos perante a lei, sem, contudo, citar expressamente a proibição da discriminação em função do sexo. Em contrapartida, no que se refere à questão do serviço militar feminino, foi pontualmente definida a exceção das mulheres neste mesmo texto constitucional de 1934: "Art. 163 - Todos os brasileiros são obrigados, na forma que a lei estabelecer, ao Serviço Militar e a outros encargos, necessários à defesa da Pátria, e, em caso de mobilização, serão aproveitados conforme as suas aptidões, quer nas forças armadas, quer nas organizações do interior. As mulheres ficam excetuadas do Serviço Militar."

Pelas vias legais do país, a possibilidade da presença de mulheres no campo militar seria algo inviável, apesar da participação recente e expressiva de mulheres nas duas frentes da Revolução Constitucionalista de 1932, guerra civil deflagrada em São Paulo, que visou à derrubada do governo provisório de Getúlio Vargas.

Aliás, neste conflito foi organizado um corpo de enfermeiras em São Paulo, o Batalhão Fernão Salles, e, do lado do governo federal, participaram alunas e professoras da Escola Anna Nery, cuja atuação foi reconhecida por parte das altas autoridades militares do Exército. Com efeito, a atuação de enfermeiras nesse conflito civil contribuiu para ampliar e projetar a enfermagem no imaginário da sociedade brasileira, como já acontecia em outros países, avançando para além das atividades de prevenção de doenças, eis que manifestavam alguma competência para compor as equipes de saúde em situações de conflito bélico(18).

A experiência prévia e, a priori, bem sucedida de aproveitamento da enfermagem na Revolução
Constitucionalista seria a base para a escolha da enfermeira como um emblema em torno do qual o Estado Novo (1937-1945), regime ditatorial e autoritário de Getúlio Vargas, constituiria um ideal de mulher e de mobilização feminina(18).

Enquanto o país experimentava efetivas aproximações de enfermeiras com os cenários e práticas militares, ideias de aparente aversão ao serviço militar feminino irrompiam. Um bom exemplo são as de Antonieta Barros, mulher que alcançou a primazia de ter sido eleita deputada na Assembleia Legislativa do Estado de Santa Catarina em 1934, e que, de certo modo, maculou estereótipos relacionados à etnia, classe social e gênero(19).

Antonieta, ao comentar notícias que vinham do Rio de Janeiro em uma crônica, comemorou que, em Convenção Eleitoral Feminina, as mulheres unanimemente votaram contra o serviço militar feminino, repudiando-o. No trecho a seguir, publicado no jornal República em 12 de março de 1933, pode-se notar o desencanto dela com "a ciência e a conduta das criaturas do século XX"(19): “(...) E não será, dentro das trincheiras, sob o matracar das metralhas, e o trovejar surdo dos canhões, frutos da ciência, postos à disposição da ganância dos homens, que conseguiremos fazer despertar na alma dos que ainda não divisaram, não compreenderam a maravilhosa finalidade da vida, todo o encanto feiticeiro da fraternidade. Não será nesse ambiente de destruição que se hão de formar caracteres puros e que se produzirá a luz, sobre as trevas que sitiam as criaturas do século XX. (...) Assim, não é medo de cumprir o dever, mas a compreensão nítida, clara, desse dever, que a obriga a rebelar-se."

À primeira vista, o discurso desta deputada, que negava com veemência a participação de mulheres nas trincheiras, reforçou de alguma maneira os papéis que cada um (homem e mulher) deveria assumir na sociedade e, em especial, nos cenários de guerra. Guardadas as devidas proporções e a despeito de suas ideias humanitárias, algum tempo depois este tipo de discurso se chocaria com as estratégias de manipulação ideológica, que seriam utilizadas pelo governo brasileiro na mobilização de homens para combaterem no front, e de mulheres para atuarem na retaguarda da Segunda Guerra Mundial, como enfermeiras. Tal situação remete à ideia de que a mulher faz parte de um exército de reserva, 
sempre em prontidão para atender quando solicitada, inclusive em "ambientes de destruição".

Há que se referendar que o período compreendido entre as duas guerras mundiais foi de grande desassossego, em virtude dos países derrotados da Primeira Guerra (1914-1918) se mostrarem insatisfeitos com sua sorte. A Grande Depressão (1929)* levou as pessoas a aceitarem qualquer tipo de liderança que desse condições de lhes devolver a prosperidade. Os bolcheviques conquistaram a Rússia; Benito Mussolini e o fascismo tomaram o controle da Itália; Hitler e o Partido Nazista se tornaram cada vez mais poderosos na Alemanha; na Espanha, instalou-se a Guerra Civil; enquanto a Inglaterra e França estavam embebidas em desavenças internas. Não era de se estranhar que surgiria e floresceria uma era ditatorial em muitos países, como inclusive aconteceu no Brasil com a instalação do Estado Novo por Getúlio Vargas, em 1937. Além disso, também se produziriam grandes mudanças de alianças, pois a Itália e o Japão, que antes haviam estado do lado aliado, se uniriam à Alemanha para formar o chamado Eixo, acordo com fortes características militares e com planos de conquistas territoriais elaborados em comum ${ }^{(9,20)}$.

Como resultado da deterioração progressiva das relações internacionais, das crises econômicas, dos milhões de desempregados, além do surgimento desses governos totalitários com fortes objetivos militaristas e expansionistas é que, durante a segunda metade da década de 1930, voltou-se a instalar a guerra na Europa. Uma guerra total que traria consequências radicais à enfermagem e aos serviços de saúde, já que o conflito afetaria a cada homem, mulher e criança dos países beligerantes $^{(9)}$.

Em 1942, por imposição da política internacional e do Pan-Americanismo, o Brasil entrou no conflito com a declaração de guerra à Alemanha Nazista. Em consequência, o governo passou a envolver suas enfermeiras às urgências e aos apelos da Segunda Guerra Mundial, fazendo com que respondessem a uma política que associava o serviço ao próximo ao serviço à pátria. Esta "política" permitiu consolidar um front interno, e impor um regime de mobilização e subordinação da sociedade às pretensões do Estado Novo, fazendo convergir políticas de saúde e saneamento com políticas

* A Grande Depressão foi uma depressão econômica que teve início em 1929 , e que persistiu ao longo da década de 1930, terminando apenas com a Segunda Guerra Mundial. É considerada o pior e o mais longo período de recessão econômica do século $X X$, por provocar altas taxas de de militarização e enquadramento forçado da população ${ }^{(18)}$.

Nessa missão, a propaganda se fez ponto de apoio fundamental no sentido de conclamar as enfermeiras do país, seja em programas de rádio, jornais ou capas de revistas. Era a imprensa estadonovista a serviço dos interesses da Pátria para a criação de uma atmosfera auspiciosa de guerra. A capa da revista semanal $O$ Cruzeiro, de grande penetração nacional à época, é um bom exemplo:

Figura 1: Capa da Revista O Cruzeiro, 1943.

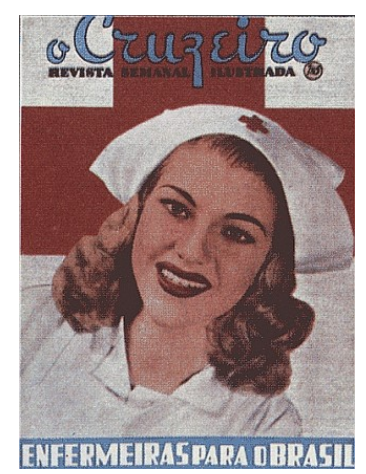

Nesta capa vê-se a imagem de uma jovem e bela enfermeira que, de algum modo, lembra o tipo físico de enfermeira veiculado nas revistas e pôsteres norteamericanos da mesma época(21). Está ela bem maquiada e penteada, seus traços são expressivos, veste uniforme branco, e está sorridente. À sua retaguarda está a imagem de uma cruz vermelha, e na borda inferior, a inscrição "enfermeiras para o Brasil". A face sorridente dessa figura feminina aliada à inscrição na capa permite às leitoras (mulheres brasileiras) a adoção do pensamento (inculcação) de que, ao aderirem ao chamado, teriam a garantia de que também ficariam satisfeitas com esta decisão: de servirem à Pátria como enfermeira. Ademais, o próprio uso de seu uniforme associado à estampa da cruz vermelha, enquanto representações objetais ostentadas no texto imagético, evidenciam os tempos de guerra, ao tempo que são produto de estratégias de interesse e manipulação, porque criam representações mentais a respeito de tais representações objetais consoantes com a ideologia que se pretende inculcar, no caso em questão, a conclamação de enfermeiras para servir à pátria.

desemprego, quedas drásticas do produto interno bruto de diversos países, bem como quedas siginificativas na produção industrial, preços de ações, e em praticamente todo medidor de atividade econômica, em diversos países no mundo. 
Esta e outras propagandas veiculadas à época visavam produzir estímulos para que as mulheres viessem a se inscrever nos cursos de enfermagem de guerra, e, após frequentá-los, transformarem-se em voluntárias. Assim, o Estado Novo tornou a profissão de enfermagem uma importante meta nacional.

A divulgação da benemérita imagem da enfermeira brasileira, na lógica de guerra que se esquadrinhava, associava-se ao imaginário da presença materna nos campos de batalha, que aliviaria a dor e o sofrimento dos soldados feridos. Por esta forma, a guerra aparecia como um momento de máxima dramaticidade, capaz de pôr à prova todas as características altruísticas de servir ao Estado e a Pátria ${ }^{(4,18)}$.

Juntamente com a profissão de professora primária, a enfermagem era uma das atividades mais exercidas pelas mulheres, desde o final do século XIX. Seu exercício constituía uma forma de afirmação profissional e de possibilidade de ascensão social para as mulheres de classe média(22). Com o avanço da Segunda Guerra, a enfermagem passa a acumular um capital simbólico que se fez servível na intensificação da formação de novas turmas de enfermeiras no início da década de 1940.

Nesta empreitada de chamamento e prontidão de enfermeiras, a Cruz Vermelha Brasileira teve uma função destacada e reconhecida na formação de um grande contingente para atuar em situações de conflito, através dos cursos de emergência de socorristas e de samaritanas realizados em várias partes do território nacional. Às suas alunas era reproduzido um discurso de cumprimento do compromisso sagrado de oferecer o quanto houvesse de esforço, caridade, abnegação e carinho para bem servir, amparar e assistir aos que, indistintamente, recorressem à enfermagem(18).

Além da Cruz Vermelha, outra instituição que se fez ver neste contexto foi a Escola Anna Nery, que, já em 1939, em aproveitamento do clima de tensão e com a possibilidade de o país enviar tropas para combater na guerra, realizou o seu primeiro curso de voluntárias. Esta iniciativa teve a finalidade de convocar moças da sociedade carioca para serem treinadas, a fim de atuarem nos hospitais da cidade, onde ocupariam o lugar de enfermeiras que, possivelmente, se engajariam para servir nos hospitais de campanha.

Essas demonstrações de afinidades entre a enfermagem e as coisas do universo militar eram estratégicas para ambos os lados. No caso da enfermagem, a adesão ao apelo patriótico dava visibilidade à profissão, mediante a divulgação de sua importância em situações de conflito. Nesse sentido, fezse explícita a incorporação de representações objetivas das estruturas militares, como o sentido de prontidão, de alerta, de marcha e de abnegação. Não por acaso, constata-se, em diversos registros fotográficos de rituais das escolas de enfermagem da época, a presença habitual e destacada de oficiais de alta patente. Do lado militar, tais aproximações poderiam garantir a intensificação do preparo de enfermeiras profissionais e voluntárias que, pela contingência de guerra, serviriam aos interesses da Nação, o que foi concretamente fortalecido quando o Brasil colocou-se em definitivo do lado dos países Aliados (especialmente dos Estados Unidos) durante a Segunda Guerra.

Com a organização da Força Expedicionária Brasileira pelo Exército e do $1^{\circ}$ Grupo de Caça pela Aeronáutica, corporações que foram formadas ao todo por cerca de 26 mil cidadãos, a criação oficial de quadros de enfermeiras militares passou a ser objeto de atenção por parte do governo federal. E aqui cabe um adendo, pois, mesmo contando o Exército com homens enfermeiros já formados e treinados, ao combater junto aos militares norte-americanos, as Forças Armadas do país tiveram que se haver com a novidade de incorporar mulheres enfermeiras nos seus Serviços de Saúde, uma vez que o Exército Norte-Americano somente mantinha corpos de enfermagem compostos exclusivamente por mulheres. Ao que se crê, este deveria ser o padrão a ser enquadrado e atendido pelas Forças do país.

Uma das enfermeiras brasileiras voluntárias, que participaram da Força Expedicionária Brasileira, esclarece mais sobre tal situação(23):

Embora a profissão de enfermagem seja eminentemente feminina, o Exército só tinha, até então, enfermeiros masculinos. [Fomos] alertados pelos americanos de que a Força Expedicionária deveria levar o seu próprio corpo de enfermeiras, não só para facilitar o entendimento entre pacientes e enfermagem, como também porque as suas profissionais já estavam sobrecarregadas de serviços. Foi aí então que o Brasil se viu premido a organizar o Curso de Emergência de Enfermeiras da Reserva do Exército e, dentre as que terminaram esses cursos, selecionou as que seguiram para a Itália. 
Também, a ida de mulheres para um cenário de guerra foi associada a uma política governamental de mobilização da população civil. As 67 enfermeiras que acompanharam as tropas do Exército e as seis incorporadas à Aeronáutica foram mobilizadas com funções claramente definidas, de suporte aos combatentes nos hospitais de campanha norteamericanos $^{(4)}$. A fotografia a seguir estampa algumas das que realizaram o Curso de Emergência de Enfermeiras da Reserva do Exército, uma das condições necessárias para a seleção das voluntárias que seguiriam para a guerra:

Figura 2: Treinamento de ordem unida com uma das turmas de enfermeiras do Exército, Colégio Militar do Rio de Janeiro, 1944

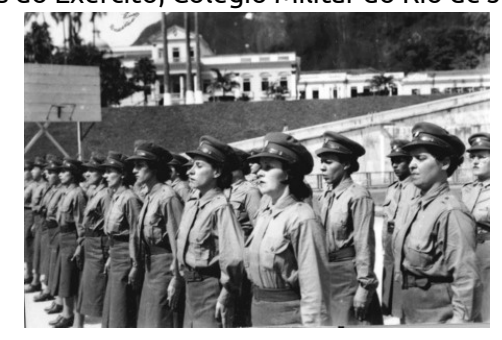

O texto fotográfico, além de atestar a inclusão feminina no âmbito do Exército, também entrevê os modos pelos quais o espírito de doação daquelas enfermeiras foi explorado pelo Estado Novo, através das contingências da guerra. A foto comunica a necessidade de incorporação de normas de conduta do campo militar consoantes com as expectativas e prescrições de um cotidiano tido como masculino em sua essência. A incorporação dessas normas se expressa através de signos incorporados como a pose, a postura, a expressão facial e a padronização de gestos, os quais, conjugados com signos exteriores ao corpo, como as fardas, enunciam as marcas simbólicas da nova posição social ${ }^{(24)}$.

Diversas imagens publicadas pela imprensa da época deste grupo de enfermeiras constituíram-se em uma forma privilegiada de promoção de sua representação, uma vez que reforçou sua identidade singular em uma sociedade que estava em constante e densa transformação. Esta "invenção do grupo" promovia um tipo de representação social esperado e desejado: da enfermeira altruísta, que atendia ao chamamento pátrio e que promoveria a extensão dos papéis das mães, filhas e esposas devotas nos campos de batalha, mas também, da mulher moderna que ousava estar "fora de lugar", e que desejava distinção social.
Entretanto, estas primeiras enfermeiras tiveram algumas dificuldades, pois, logo no início de sua incorporação ao Exército, não tiveram elas direito a posto militar. A situação dessas "civis fardadas" só foi resolvida mais tarde pelas autoridades militares, com a promoção delas ao posto de $2^{\circ}$ tenente já no Teatro de Operações, na Itália. Outra dificuldade se deu com o pagamento, pois elas não receberam soldos correspondentes aos seus postos de $2^{\circ}$ tenente, mas de $2^{\circ}$ sargento, ao longo de toda a sua participação na guerra. Este episódio demonstra os limites do Exército em lidarem com a questão de inclusão de um contingente feminino aos seus quadros, mas também reflete os esquemas de dominação que desfavoreciam as mulheres no mundo do trabalho à época.

Apesar do precedente aberto por estas enfermeiras, elas somente participaram do corpo efetivo das Forças Armadas enquanto durou a guerra, pois, logo após o seu término em 1945, todas foram desmobilizadas, o que explicita a resistência acerca das possibilidades de permanência de mulheres neste campo ${ }^{(4)}$.

Com efeito, se a relação de enfermeiras com os exércitos foi de certa forma possível e até requerida durante as guerras, o mesmo não ocorria com tanta semelhança quando a questão era a incorporação de segmentos femininos de enfermagem nas corporações militares em tempos de paz. Mesmo porque, "em todo o caso, as brechas abertas pelas guerras são rapidamente fechadas quando volta a paz, sobretudo no que se refere ao trabalho e aos papéis privados."(7)

Contudo, cabe o ressalte de que estas mesmas enfermeiras, que cuidaram dos soldados brasileiros e estrangeiros na Segunda Guerra, passaram a adotar uma série de medidas estratégicas em diversas situações de um "novo front", que objetivou sua reinclusão no Serviço Militar Ativo do Exército e da Aeronáutica. Aliás, tal pleito estava afinado com o quadro da anunciada igualdade dos sexos no pós-guerra, quando passou a existir um direito de acesso irrestrito da mulher à plena condição militar, através da Carta da recém criada Organização das Nações Unidas, de 1945, e da Declaração Universal dos Direitos do Homem, de 1948. Mas, quanto à realidade, existiram aqui e acolá, segundo as tradições culturais e religiosas de cada país, limitações maiores ou menores. No entanto, com o passar do tempo, ficou evidente que a presença feminina nas instituições militares seria algo irreversível. 
No caso nacional, com o capital social e simbólico acumulado pelas enfermeiras brasileiras em razão de sua atuação no campo militar durante a Segunda Guerra, com as alianças arquitetadas com alguns generais comandantes e parlamentares influentes, e por meio da reprodução de um discurso patriótico, idealizado e legitimador de sua atuação pública nos tempos de guerra em diversos cenários e circunstâncias, elas conseguiram que dois projetos de lei fossem aprovados, que originaram a Lei 3.160/1957, para as enfermeiras do Exército, e a Lei n³.632/1959, para as da Aeronáutica. Assim, tornaram-se as primeiras enfermeiras militares do país, em tempo de paz, quando passaram a gozar dos direitos, vantagens e regalias inerentes aos oficiais da ativa, sendo distribuídas por diversas organizações militares de saúde espalhadas pelo território nacional, mas ainda com limites sobre a ascensão hierárquica, pois só puderam chegar ao posto máximo de capitão(1).

Como resultado desse processo, estas enfermeiras acabaram promovendo uma imagem-tipo de enfermeira militar no país, que se colocou em evidência no Estado Novo, e que, guardadas as devidas proporções, tenderia a se consolidar em um contexto desenvolvimentista, como um sinal do caráter modernizador que as Forças Armadas Brasileiras passaram a perseguir após a Segunda Guerra Mundial, inclusive, no avanço de sua enfermagem. Mesmo porque, o que passou a estar em discussão no pós-guerra, inclusive nos primeiros congressos brasileiros de medicina militar que começaram a ser organizados a partir de 1954, foi a admissão de enfermeiras de alto padrão (com nível superior) nos Serviços de Saúde das Forcas Armadas, o que só viria a acontecer, de fato, nas últimas décadas do século $\mathrm{XX}$, quando a já desgastada Ditadura Militar (1964-1985) precisa suavizar os efeitos negativos de sua imagem e representação junto à opinião pública com a admissão estratégica de mulheres nas Forças Armadas, tentando demonstrar, com isso, uma faceta mais democrática ${ }^{(1)}$.

Há que se referendar que a Marinha começou a incorporar candidatas do sexo feminino as suas fileiras somente em 1980, quando foi criado o Corpo Auxiliar Feminino da Reserva da Marinha para oficiais e graduados. Já a Aeronáutica resolveu reabrir suas portas às mulheres em 1981 através da formação de seu Corpo Feminino da Reserva da Aeronáutica, destinado a oficiais e graduados. $E$, na sequência, o Exército também retomou a incorporação de mulheres em 1989, quando criou o
Quadro Complementar de Oficiais do Exército, para o ingresso de oficiais temporários ou de carreira.

\section{CONSIDERAÇÕES FINAIS}

Neste estudo foram ressaltados alguns marcos e marcas da história da enfermagem militar no Brasil. Nos resultados apresentados, evidenciou-se que as primeiras iniciativas de incorporação oficial de mulheres enfermeiras no Serviço Militar, as quais culminaram com a criação de quadros de enfermeiras no Exército e na Aeronáutica em 1943 e 1944, respectivamente, deram uma nota prévia do que seria a criação dos quadros femininos de enfermagem no âmbito das Forças Armadas, a partir da década de 1980.

Outrossim, a história da incorporação oficial de mulheres enfermeiras no Serviço Militar do país pode ser entendida como uma história de luta e resistência, mas também de adequação ao contexto político-social, quando as relações de poder, em dadas circunstâncias, redefiniram a divisão sexual do trabalho nos espaços militarizados. Neste processo, encetado com afinco no período entre guerras, as questões de gênero evidenciaram uma luta propriamente simbólica, em que a busca por igualdade e inclusão era o que estava em jogo.

Com certeza, muitos limites daquela época foram ponderados e superados. No momento presente, é de causar certa perplexidade o tipo de sorte que tiveram aquelas enfermeiras há algumas décadas atrás. E aí, seria algo oportuno atribuir às mudanças percebidas simplesmente ao avanço dos tempos e das novas mentalidades. Entretanto, não devem ser esquecidas as pessoas concretas que, vivendo naquele contexto ardiloso com ideias diferentes, ousadia e coragem, fizeram com que fosse possível, hoje, a coexistência frutífera de homens e mulheres no campo militar ${ }^{(25)}$.

Рага assegurar a construção deste estudo, foram tratadas com rigor teórico-metodológico diversas fontes históricas. Mas, alertamos aos leitores que, todo produto final de análise derivado de uma pesquisa histórica deve ser sempre considerado provisório e aproximado, já que a totalidade de qualquer acontecimento passado é praticamente irrecuperável. Tal condição torna este tipo de pesquisa desafiadora, trabalhosa e complexa, mas também instigante e necessária. Ademais, o (re)conhecimento dos processos históricos que envolveram a prática de enfermagem em diversos tempos, lugares e circunstâncias favorecem àqueles que 
a exercem a tomada de consciência de sua identidade profissional, construída historicamente, mas também de suas possibilidades de melhor desenvolverem

\section{REFERÊNCIAS}

1. Oliveira AB. Enfermeiras da Força Expedicionária Brasileira no front do pós-guerra: o processo de reinclusão no Serviço Militar Ativo do Exército (1945-1957) [tese]. Rio de Janeiro: Escola de Enfermagem Anna Nery/UFRJ; 2010. 299 p.

2. Oliveira AB, Santos TCF, Barreira IA, Lopes GT, Almeida Filho AJ, Amorim WM. Enfermeiras brasileiras na retaguarda da Segunda Guerra Mundial: repercussões dessa participação. Texto Contexto Enferm [Internet]. 2009 [acesso em: 30 set 2013];18(4):688-96. Disponível em:

http://dx.doi.org/10.1590/S0104-07072009000400010.

3. Bernardes MMR, Lopes GT. As enfermeiras da força expedicionária brasileira no front italiano. Rev Esc Enferm USP [Internet]. 2007 [acesso em: 30 set 2013];41(3):447-53. Disponivel em: http://dx.doi.org/10.1590/S008062342007000300015.

4. Oliveira AB, Santos TCF, Barreira IA, Almeida Filho AJ. The nurses of the Brazilian expeditionary force and the dissemination of their return home. Rev Lat Am Enfermagem [Internet]. 2009 [acesso em: 30 set 2013];17(6):1050-6.

Disponivel em: http://dx.doi.org/10.1590/S0104-

11692009000600019.

5. Barros JA. O projeto de pesquisa em História: da escolha do tema ao quadro teórico. 2a ed. Petrópolis: Vozes; 2005. 236 p. 6. Bourdieu P. A dominação masculina. 4a ed. Tomaz F, tradutor. Rio de Janeiro: Bertrand Brasil; 2003. 322 p.

7. Perrot M. As mulheres ou os silêncios da história. Ribeiro V, tradutor. Bauru: Edusc; 2005. 520 p.

8. Caire R. A mulher militar. Brízida JO, tradutor. Rio de Janeiro: Biblioteca do Exército; 2002.336 p.

9. Donahue MP. Historia de la enfermeria. Picazo M, Hernández C, tradutor. Barcelona: Doyma; 1985. 506 p.

10. Costa R, Padilha MI, Amante LN, Costa E, Bock LF. O legado de Florence Nightingale: uma viagem no tempo. Texto Contexto Enferm [Internet]. 2009 [acesso em: 30 set 2013];18(4):661-9. Disponivel em: http://dx.doi.org/10.1590/S010407072009000400007.

11. Batista DO. O mito Anna Nery e a Enfermagem Brasileira [dissertação]. Rio de Janeiro: Escola de Enfermagem Anna Nery/UFRJ; 2005. 117 p.

12. Armeny S. Organized nurses, women philanthropists, and the intellectual bases for cooperation among women, 18981920. In: Lagemann EC. Nursing history: new perspectives, new possibilities. New York: Teachers College Press; 1983.

13. Porto F, Santos TDF. A divulgação da competência técnica em socorro das enfermeiras da cruz vermelha (SP) nas circunstâncias da Primeira Guerra Mundial (1917-1918). Rev. Eletr. Enf. [Internet]. 2006 [acesso em: 30 set 2013];8(2):273-81. Disponível em:

http://www.fen.ufg.br/revista/revista8 2/v8n2a12.htm.

14. Soihet R. A pedagogia da conquista do espaço público pelas mulheres e a militância feminista de Bertha Lutz. Rev. Bras. Educ. [Internet]. 2000 [acesso em: 30 set 2013];(15):97-117. Disponível em:

http://www.scielo.br/scielo.php?script=sci arttext\&pid=S141324782000000300007\&lng=en\&nrm=iso.

15. Araújo RCB. O voto de saias: a Constituinte de 1934 e a participação das mulheres na política. Estud. av. [Internet]. 2003 [acesso em: 30 set 2013];17(49):133-50. Disponível em: http://dx.doi.org/10.1590/S0103-40142003000300009. criticamente a profissão no presente, e quiçá fazê-la avançar no futuro.

16. Barreira IA, Baptista SS, Sauthier J, Santos TCF, Peres MA, Oliveira AB et al. Primeira República: a implantação da enfermagem laica e seus desdobramentos (1889-1930). In: Padilha MI, Borenstein MS, Santos I, organizadores.

Enfermagem: história de uma profissão. São Caetano do Sul: Difusão; 2011. p. 219-52.

17. Marson MI. Da feminista "macha" aos homens sensíveis: o feminismo no Brasil e as (des)construções das identidades sexuais. Cadernos AEL [Internet]. 1996 [acesso em: 30 set 2013];2(3/4):69-110. Disponível em:

http://segall.ifch.unicamp.br/publicacoes ael/index.php/cadern os ael/article/view/143.

18. Cytrynowicz R. A serviço da pátria: a mobilização das enfermeiras no Brasil durante a Segunda Guerra Mundial. Hist Cienc Saude Manguinhos [Internet]. 2000 [acesso em: 30 set 2013];7(1):73-91. Disponível em:

http://dx.doi.org/10.1590/50104-59702000000200004.

19. Nunes KLD. Antonieta de Barros: uma história [dissertação]. Florianópolis: Centro de Filosofia e Ciências Humanas/UFSC; 2001. $159 \mathrm{p}$.

20. Boris F. O pensamento nacionalista autoritário: 1920-1940. Rio de Janeiro: Jorge Zahar; 2001.

21. Rubino MA. The Art of War: Visual Propaganda and American Military Recruiting. An Annotated Bibliography [dissertation] [Internet]. Chapel Hill: University of North Carolina; 2007 [acesso em: 30 set 2013]. Disponível em: http://dc.lib.unc.edu/cdm/singleitem/collection/s_papers/id/96 3.

22. Santos TCF, Barreira IA. A mulher e a enfermeira na nova ordem social do Estado Novo. Texto Contexto Enferm [Internet]. 2008 [acesso em: 30 set 2013];17(3):587-93. Disponivel em: http://dx.doi.org/10.1590/S010407072008000300021.

23. Cansanção E. E foi assim que a cobra fumou. 3a ed. Rio de Janeiro: Imago; 1987.239 p.

24. Oliveira AB, Santos TCF. Condecorações de guerra como investidura de bens simbólicos às ex-enfermeiras febianas. Esc. Anna Nery [Internet]. 2010;14(1):19-25. Disponível em: http://dx.doi.org/10.1590/S1414-81452010000100004. 25. Bassanezi C. Mulheres dos anos dourados. In: Del Priore M, organizador. História das mulheres no Brasil. 8a ed. São Paulo: Contexto; 2006. p. 607-39.

Artigo recebido em 10/03/2012. Aprovado para publicação em 15/04/2013. Artigo publicado em 30/09/2013. 